
총담관결석

연세대학교 원주의과대학 ${ }^{1}$ 내과학교실, ${ }^{2}$ 외과학교실

하성삼 $^{1} \cdot$ 임유리 $^{1} \cdot$ 이지현 ${ }^{1} \cdot$ 심정한 $^{1} \cdot$ 유진세 $^{1} \cdot$ 이경주 $^{1} \cdot$ 김동현 $^{2} \cdot$ 김재우 $^{1}$

\title{
Common Bile Duct Stone Caused by Migrated Surgical Clip 10 Years after Laparoscopic Cholecystectomy
}

\author{
Sung Sam Ha', Yoo Ri Lim', Ji Hyeon Lee', Jeong Han Sim', Jin Sae Yoo', Kyong Joo Lee', \\ Dong Hyun $\mathrm{Kim}^{2}$, Jae Woo Kim \\ Department of Internal Medicine, ²Department of Surgery, Yonsei University Wonju College of Medicine, Wonju, Korea
}

Rarely, surgical clips can migrate into the biliary tract after laparoscopic cholecystectomy and work as a nidus for biliary stone formation. We report a case of the development of a common bile duct (CBD) stone induced by surgical clip in a 57-yearold man who underwent laparoscopic cholecystectomy 10 years ago. On computed tomography, a CBD stone with a metallic material was found, and endoscopic retrograde cholangiopancreatography (ERCP) revealed a CBD stone including a metallic clip. The stone was removed completely by ERCP, and the surgical clip was found along with the stone.

Korean J Pancreatobiliary 2015;20(1):42-45

Keywords: Surgical instrument, Migration, Common bile duct calculi, Cholecystectomy

\author{
Received Oct. 13, 2014 \\ Revised Nov. 12, 2014 \\ Accepted Dec. 11, 2014
}

Corresponding author: Kyong Joo Lee

Division of Gastroenterology and Hepatology, Department of Internal Medicine, Yonsei University Wonju College of Medicine, 20 Ilsan-ro, Wonju 220-701, Korea

Tel. +82-33-741-1221 Fax. +82-33-741-1228

E-mail; smild123@yonsei.ac.kr
This is an Open Access article distributed under the terms of the Creative Commons Attribution Non-Commercial License (http:// creativecommons.org/licenses/by-nc/3.0/) which permits unrestricted non-commercial use, distribution, and reproduction in any medium, provided the original work is properly cited.

Copyright $\odot 2015$ by The Korean Journal of Pancreas and Biliary Tract

\section{서 론}

복강경 담낭절제술은 증상있는 담낭 결석 및 담낭 용종 치 료의 주된 치료 방법이며, 비교적 안전한 치료법이다. 복강 경 담낭절제술 때 사용되는 외과용 클립은 간혹 합병증으로 담즙 누출, 담도 협착, 총담관 누공, 급성 췌장염, 담관염 등 을 일으킬 수 있다. 매우 드물게는 복강경 담낭절제술 후 외 과용 클립이 총담관 내로 이동하여 총담관 결석이 발생하는
경우와 클립으로 인한 색전증 등이 보고되고 있다. ${ }^{1-4}$ 복강경 담낭절제술 후 외과용 클립이 이동하여 총담관 결석이 발생 한 증례는 1982년 처음 보고된 이래 매우 드물지만, 꾸준히 보고되고 있으며, 이는 담낭 주위의 혈관 또는 담낭관을 결 찰할 때 사용되는 외과용 클립이 총담관 내로 이동하면서 총 담관 내 결석 형성의 핵(nidus)으로 작용하여 발생할 것으로 생각된다. ${ }^{5,6}$ 복강경 담낭절제술 후 담관결석으로 인해 첫 증 상이 나타나기까지의 기간은 11 일에서 10 개월 사이로 짧은 


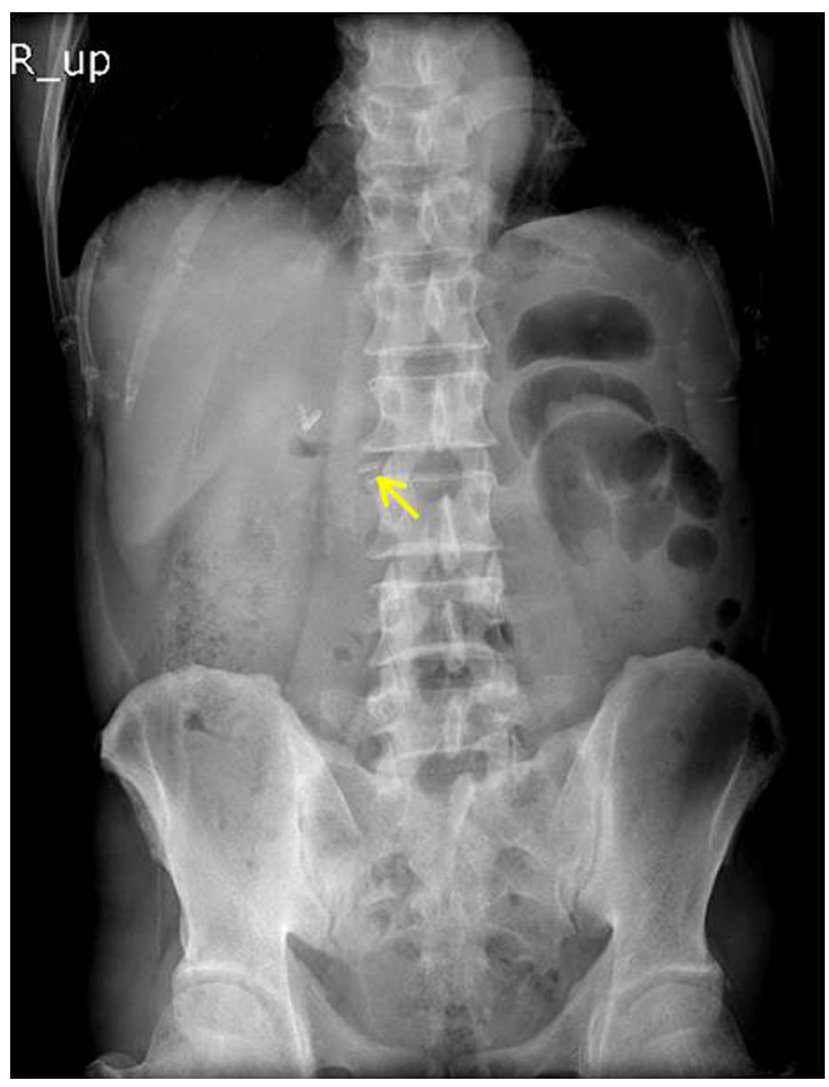

Fig. 1. Plain abdominal X-ray. A metallic material (arrow) is found apart from a few metallic materials.

편이다. ${ }^{7}$ 저자들은 복강경 담낭절제술을 받고 10 년이 지난 후 외과용 클립으로부터 발생한 총담관 결석 1 예를 내시경 적으로 치료하였기에 보고하고자 한다.

\section{증 례}

58 세 남자환자가 내원 1 일 전 발생한 명치부위의 쥐어짜 는 듯한 통증, 오심, 구토로 응급실에 왔다. 환자는 10 년 전 다른 종합 병원에서 담낭 용종으로 복강경 담낭절제술을 받 았으며, 1 년 전 간농양으로 항생제 치료를 받은 적이 있었다. 그외 고혈압으로 약물복용 중이었다. 내원 당시 활력징후는 혈압 $138 / 87 \mathrm{mmHg}$, 맥박수 78 회/분, 호흡수 20회/분, 체온 은 $36.7^{\circ} \mathrm{C}$ 였으며, 신체 검진에서 중등도의 명치부위 및 우상 복부의 압통이 관찰되었다. 말초혈액검사에서 백혈구 수 $7,270 / \mathrm{mm}^{3}$ (호중구 $82.0 \%$, 림프구 $11.0 \%$, 단핵구 $4.4 \%$ ), 혈 색소 $14.2 \mathrm{~g} / \mathrm{dL}$, 헤마토크릿 $40.2 \%$, 혈소판 $171,000 / \mathrm{mm}^{3}$ 였 다. 일반 생화학 검사에서 AST $266 \mathrm{U} / \mathrm{L}, \mathrm{ALT} 163 \mathrm{U} / \mathrm{L}$, 알칼 리 포스파타제 $102 \mathrm{U} / \mathrm{L}$, 감마-글루타밀전이효소 $197 \mathrm{U} / \mathrm{L}$,

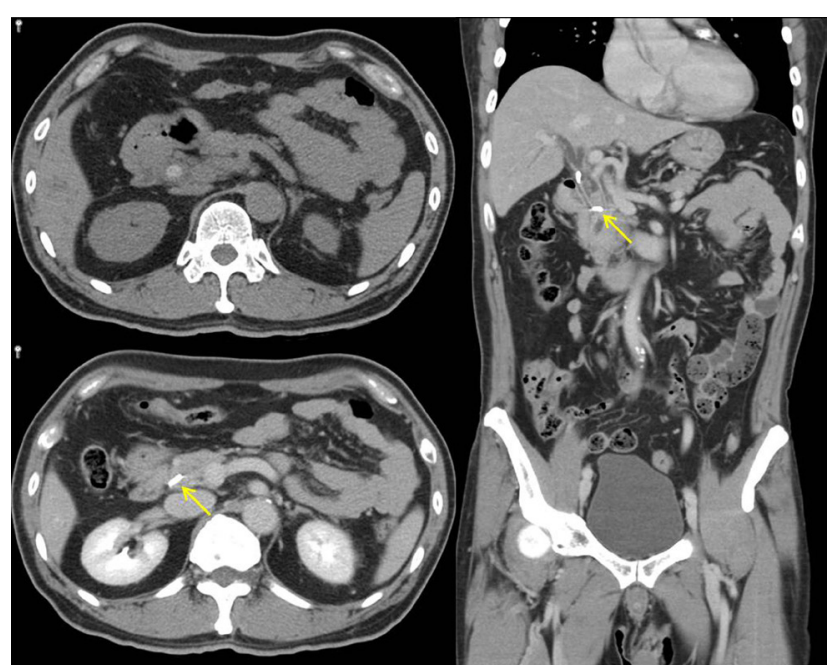

Fig. 2. Contrast-enhanced abdomino-pelvic computed tomography. Radio-opaque stone around metallic material (arrow) is revealed in common bile duct.

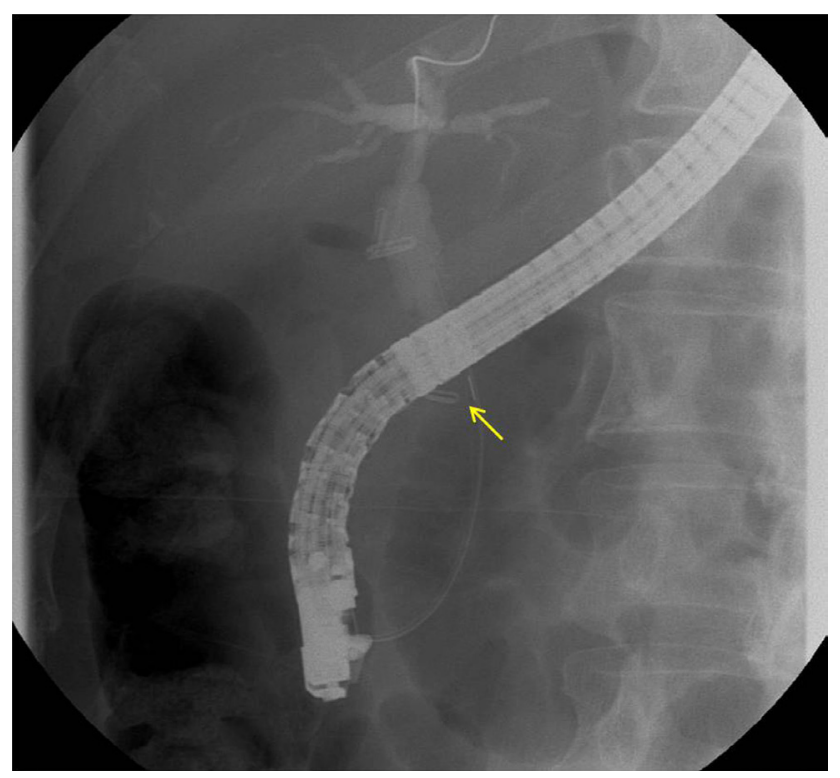

Fig. 3. Round-shaped filling defect, including a radio-opaque material, possibly a surgical clip (arrow), is found at mid-common bile duct.

총 빌리루빈 $3.05 \mathrm{mg} / \mathrm{dL}$, 직접 빌리루빈 $1.27 \mathrm{mg} / \mathrm{dL}$, 알부민 $4.3 \mathrm{~g} / \mathrm{dL}, \mathrm{C}$ 반응성 단백은 정상이었다. 단순 복부촬영에서 금속성 물질이 담관으로 추정되는 부위에서 관찰되었으며 (Fig. 1), 복부 전산화단층촬영에서 경도의 총담관 확장, 총 담관 결석과 결석 내부에 $12 \mathrm{~mm}$ 크기의 금속성 물질이 관찰 되었다(Fig. 2). 내시경적 역행성 담췌관조영술(endoscopic retrograde cholangiopancreatography, ERCP)에서 경도의 총담관 확장 및 중심부에 외과용 클립으로 생각되는 방사선 비투과성 물질을 포함한 비교적 원형의 총담관 내의 음영결 


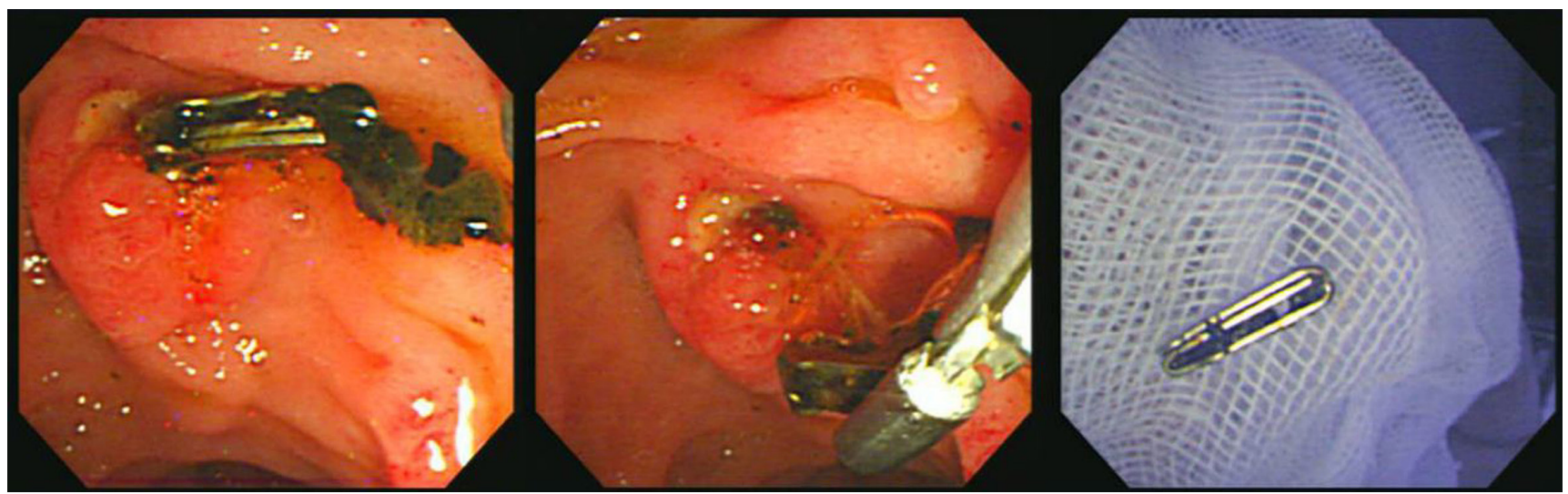

Fig. 4. Common bile duct stone and surgical clip are removed by basket and balloon catheter.

손과 더불어 담낭관 기부로 판단되는 부위에 2 개의 외과용 클립이 발견되었다(Fig. 3). 환자는 아스피린 복용 중이었으 며, 출혈의 위험도를 고려하여 내시경적 역행성 담즙배액술 을 먼저 시행하였다. 입원 후 체온이 $38.3^{\circ} \mathrm{C}$ 으로 발열 소견이 있었으며 백혈구 $14,100 / \mathrm{mm}^{3}, \mathrm{C}$ 반응성 단백은 $7.64 \mathrm{mg} / \mathrm{dL}$ 까지 상승하였다. 경험적 항생제를 사용하였고 응급실 내원 당시 시행했던 혈액 배양검사에서는 녹농균이 동정되었고 사용 중인 항생제에 민감하여 유지하였다. 담즙배액술을 시 행하고 항생제를 사용하면서 통증은 감소하고 발열은 해소 되었다. 보존적 치료 5일 후 총담관결석을 제거하기 위하여 내시경적 역행성 담췌관 조영술을 시행하였다. 담관으로 선 택적 삽관후 유두괄약근절개술을 시행하였을 때 다량의 농 이 배출되었다. 바스켓과 풍선 카테터를 이용하여 클립을 포 함하는 총담관 결석을 제거하였으며, 결석은 잘 부서지는 양 상이었으며, 클립은 겸자를 이용하여 체외로 제거하였다 (Fig. 4). 이후 환자는 증상이 호전되어 퇴원 후 외래 추적관 찰 중이다.

\section{고 찰}

담낭절제술 이후에 발생하는 총담관결석은 5-10\% 정도로 보고되고 있다. ${ }^{5}$ 1982년 복강경 담낭절제술을 시행한 뒤 외 과용 클립이 이동하면서 발생한 총담관결석의 예가 보고 되 었다. ${ }^{6}$ 이후에도 담낭절제술 이후 발생하는 총담관결석의 증 례들이 종종 보고되고 있으며, 이러한 증례들을 통하여 담관 내 이물질들이 결석의 형성에 영향을 준다는 사실이 널리 알 려지게 되었다.

외과용 클립에 의해 담석이 생성되는 기전은 명확하게 밝 혀진 것은 없으나, 여러 가지 가설들이 제시되고 있다. 그 중
하나는 담낭관의 불완전한 봉합, 짧은 담낭관 기부, 혹은 허 혈성 괴사에 의한 압력 증가 등으로 클립이 담관 내로 이동 한 뒤 결석의 핵으로 작용하여 점액분비를 자극하거나, 세균 의 집락화를 유발하여 담즙이 저류되고 담석의 크기가 커진 다는 것이다. ${ }^{89}$ 클립이 이동하는 데에는 여러 가지 요소들이 작용하는데, 클립을 정확하게 위치시키지 못함으로 인해 담 즙 누출 및 국소적인 감염이 발생할 수 있으며, 또한 클립의 개수 역시 중요한 요소로 지적되고 있다. 또한 담낭주변의 염증이 심한 상태에서 수술하게 되는 경우 염증에 의해 해부 학적 구조의 변형이 생겨 수술 후 염증이 호전되면서 클립의 이동이 발생할 수 있다.

임상증상은 일반적인 담관염의 증세를 나타내는데, 복부 통증이 가장 흔하며, 황달, 발열, 오심, 구토, 소화불량 등의 증상과 췌장염이 발생할 수 있다.

진단은 비침습적인 방법으로 단순 복부사진에서 클립의 위치변화가 있거나, 전산화 단층촬영검사에서 담관 내 금속 성 물질이 관찰되면 의심해 볼 수 있겠으나, 확진은 내시경 적 역행성 담관조영술을 시행하여 결석 내 금속성 클립을 확 인해야 한다.

본 증례에서는 복강경 담낭절제술후 기존 보고보다는 더 긴 시간이 지나고 나서 클립이 총담관으로 이동한 예이다. 외과용 클립과 연관된 담석발생 증례는 한 증례에서 잔존담 낭에서 클립과 연관된 담석이 14 년 후에 보고되기도 했으 나, ${ }^{10}$ 대부분 2 년 전후로 발생하는 경향이 있다. ${ }^{11}$ 복강경 담 낭절제술의 경우 개복수술보다 담도계의 손상이 크기 때문 에 짧은 기간 내에 나타나는 것으로 추측한다. ${ }^{2,12}$ 본 증례처 럼 복강경 담낭절제술 후 10 년이 지나 발생하는 경우는 극히 드물다. 국내에서도 한 차례 비슷한 증례가 보고되었으며 지 연되어 나타나는 이유는 외과용 클립이 만성적으로 담관을 
자극하고 염증을 초래하여 수술 주변 조직을 침식하여 담관 내로 들어간 것으로 생각된다. ${ }^{13}$ 내원 당시 시행한 단순 복부 사진에서 금속성 물질이 따로 떨어져 총담관으로 추정되는 부위에서 관찰되고 있었으며, 전산화 단층촬영검사에서 총 담관 내에 금속성 물질과 이를 둘러싸고 있는 총담관결석이 관찰되어 역행성 담관조영술과 내시경적 방법으로 결석 및 클립을 제거함으로써 클립에 의한 결석을 진단할 수 있었다.

향후 본 증례와 같은 담낭절제술 후 합병증을 줄이기 위해 서는 흡수성 물질로 만든 클립을 사용해 볼 수 있겠으며, 클 립을 사용하지 않는 담낭절제술을 위하여 초음파를 이용한 하모닉 스캘펄(harmonic scalpel) 등을 이용한 방법 등이 대 안이 될 수 있겠다. ${ }^{14}$ 그러나, 무엇보다 외과용 클립의 사용시 클립이 풀리지 않도록 단단히 고정하며, 담도 손상에 의한 담즙 누출을 방지하기 위해 세심한 주의가 필요하다. 또한 복강경 담낭절제술을 시행받은 후 상복부 통증을 호소하는 환자에서 클립에 의한 총담관 결석의 발생을 염두에 두고 단 순복부촬영에서 외과용 클립의 위치변화를 비교 확인하는 것이 만약에 발생할 지 모르는 합병증의 조기진단에 도움이 될 수 있을 것이다.

\section{요 약}

본 증례는 복강경 담낭절제술 후 10 년이 경과되어 발생한 총담관 결석의 예로, 결석 내 포함된 외과용 클립이 담관결 석의 원인이 되었을 것으로 추정된다. 내시경으로 제거한 총 담관결석 내에 외과용 클립이 발견되어 수술시 사용한 외과 용 클립이 총담관 내로 이동하여 총담관 내 결석의 핵으로 작용했을 가능성을 뒷받침한다. 담낭 절제술 후 발생한 우상 복부 통증으로 내원한 환자에서 외과용 클립에 의한 총담관 결석은 진단에 있어 고려해야 할 부분으로 생각된다. 진단은 단순복부촬영에서 우상복부에 금속성 물질이 관찰된다면 의심할 수 있겠으나, 내시경적 담췌관조영술에서 총담관 내 에 음영결손과 결석 내부에 금속성 물질이 관찰될 때 가능하 다. 치료는 일반적인 총담관 결석의 치료와 동일하며, 내시 경을 이용한 유두괄약근 절개술 후 바스켓 및 풍선 카테터를 이용한 결석 제거가 유용하다.

국문 색인: 외과용 클립, 이동, 담관담석, 담낭절제술

\section{Conflicts of Interest}

The author has no conflicts to disclose.

\section{REFERENCES}

1. Chong VH, Chong CF. Biliary complications secondary to post-cholecystectomy clip migration: a review of 69 cases. J Gastrointest Surg 2010;14:688-696.

2. Lee $\mathrm{KW}$, Lee JW, Jeong $\mathrm{S}$, et al. A case of common bile duct stone formed around a surgical clip after laparoscopic cholecystectomy. Korean J Gastroenterol 2003;42:347-350.

3. Mansvelt B, Harb J, Farkas B, Mourou M, Huguet C. "Clip-stone" filiation within the biliary tract. HPB Surg 1993;6:185-188.

4. Raoul JL, Bretagne JF, Siproudhis L, Heresbach D, Campion JP, Gosselin M. Cystic duct clip migration into the common bile duct: a complication of laparoscopic cholecystectomy treated by endoscopic biliary sphincterotomy. Gastrointest Endosc 1992;38:608-611.

5. Ghazanfari K, Gollapudi PR, Konicek FJ, Olivera A, Jr., Madayag M, Warner J. Surgical clip as a nidus for common bile duct stone formation and successful endoscopic therapy. Gastrointest Endosc 1992;38:611-613.

6. Walker WE, Avant GR, Reynolds VH. Cholangitis with a silver lining. Arch Surg 1979;114:214-215.

7. Matsuura T, Kanisawa Y, Sato T, Saito T, Hirata K. Migration of "endo-clips" into common bile-duct after laparoscopic cholecystectomy. Lancet 1992;340:306.

8. Kitamura K, Yamaguchi T, Nakatani $H$, et al. Why do cystic duct clips migrate into the common bile duct? Lancet 1995;346:965-966.

9. Onghena T, Vereecken L, Van den Dwey K, Van Loon C. Common bile duct foreign body: an unusual case. Surg Laparosc Endosc 1992;2:810.

10. Rajendra A, Cohen SA, Kasmin FE, Siegel JH, Leitman M. Surgical clip migration and stone formation in a gallbladder remnant after laparoscopic cholecystectomy. Gastrointest Endosc 2009;70:780-781.

11. Dell'Abate P, Del Rio P, Soliani P, Colla G, Sianesi M. Choledocholithiasis caused by migration of a surgical clip after video laparoscopic cholecystectomy. J Laparoendosc Adv Surg Tech A 2003;13:203-204.

12. Cheslyn-Curtis S, Emberton M, Ahmed H, Williamson RC, Habib NA. Bile duct injury following laparoscopic cholecystectomy. Br J Surg 1992;79:231-232.

13. Oh HJ, Jung HJ, Chai Jl, et al. A case of common bile duct stone developed due to a surgical clip as a nidus: an experience of successful management by endoscopy. Korean J Gastroenterol 2003;42:351-353.

14. Westervelt J. Clipless cholecystectomy: broadening the role of the harmonic scalpel. JSLS 2004;8:283-285. 